\title{
Effects of Transdermal Testosterone on Bone and Muscle in Older Men with Low Bioavailable Testosterone Levels, Low Bone Mass and Physical Frailty
}

\author{
Anne M Kenny, MD, Alison Kleppinger, MS, Kristen Annis, Margaret Rathier, MD, Bruce \\ Browner, MD, James O. Judge, MD, and Daniel McGee, PhD \\ Center on Aging (AMK, AK, KA, MR), New England Musculoskeletal Institute (BB), University of \\ Connecticut Health Center, Farmington, CT 06030-5215 VA Connecticut Healthcare System, \\ Newington, CT (MR) Evercare Connecticut, Hartford, CT (JOJ) Department of Statistics, Florida \\ State University, Tallahassee FL (DM) (860) 679-3956 Fax (860)679-1307
}

\begin{abstract}
Objectives-To investigate the effects of testosterone supplementation on bone, body composition, muscle, physical function, and safety in older men.

Design, Setting, Participants-Double-blind, randomized, placebo-controlled trial was done at a major medical institution of 131 men (mean $77.1 \pm 7.6 \mathrm{yr}$ ) with low testosterone level, history of fracture or bone mineral density (BMD) T-score of $<-2.0$ AND frailty.

Intervention-Participants received $5 \mathrm{mg} / \mathrm{d}$ testosterone (AndroGel ${ }^{\mathrm{TM}}$ ) or placebo for $12-24$ months; all received calcium $(1500 \mathrm{mg} / \mathrm{d}$ diet and supplement) and cholecalciferol (1000 IU/d).

Measurements-BMD of hip, lumbar spine, and mid-radius, body composition, sex and calcium regulating hormones, bone turnover markers, strength, physical performance, and safety parameters.
\end{abstract}

\begin{abstract}
Results-Ninety -nine men (75.6\%) completed 12 months and 62 men (47.3\%) completed end therapy (mean 23 months; range 16-24 months for 62 men in this group). Study adherence was $54 \%, 40 \%$ of subjects maintaining $70 \%$ or greater adherence. Testosterone and bioavailable testosterone levels at 12 months were $583 \mathrm{ng} / \mathrm{dL}$ and $157 \mathrm{ng} / \mathrm{dL}$ in the treatment group. BMD on testosterone increased $1.38 \%$ at the femoral neck, $3.25 \%$ at the lumbar spine $(\mathrm{p}=.005)$ and decreased by $1.29 \%$ at the mid-radius $(\mathrm{p}=.0008)$. There was an increase in lean mass and decrease in fat mass in the testosterone group, but no differences in strength or physical performance. Finally, there were no differences in safety parameters.
\end{abstract}

\footnotetext{
Correspondence to: Anne Kenny, MD, Center on Aging, MC-5215, University of Connecticut Health Center, Farmington, CT 06030-5215, kenny@uchc.edu.

Conflict of Interest:

The editor in chief has reviewed the conflict of interest checklist provided by the authors and has determined that the authors have no financial or any other kind of personal conflicts with this paper.

Author Contributions: Dr. Kenny was responsible for intellectual content of the paper by conception and design, obtaining funding, acquisition of data and analysis and interpretation of results, drafting and revision of the manuscript, administrative, technical and material support, and supervision. Ms. Kleppinger was responsible for analysis and interpretation of results, drafting and revision of the manuscript and technical support. Ms. Annis was responsible for acquisition of data, drafting and revision of manuscript and technical support. Dr. Rathier was responsible for intellectual content of the paper by analysis and interpretation of the results, drafting and revision of the manuscript. Dr. Bowner was responsible for intellectual content of the paper by analysis and interpretation of the results, drafting and revision of the manuscript. Dr. Judge was responsible for intellectual content of the paper by analysis and interpretation of the results, drafting and revision of the manuscript. Dr. McGee was responsible for acquisition of data, analysis and interpretation of results, and drafting and revision of manuscript. All authors give final approval to the manuscript submitted.
} 
Conclusion-Older, frail men receiving testosterone replacement increased testosterone levels, had favorable changes in body composition, modest changes in axial BMD, and no substantial changes physical function.

\section{Keywords}

testosterone; osteoporosis; frailty; hypogonadism

\section{INTRODUCTION}

Testosterone levels decline with advancing age (1). Fifty percent of men over age 65 have bioavailable testosterone levels below the reference range for young adult men (2). The importance of the decline in testosterone levels to the health of older men is uncertain, but testosterone insufficiency may play a role in age-related bone loss, muscle weakness $(3,4)$ and frailty (5). We, and others, have found encouraging results in bone density changes when relatively healthy, not overtly testosterone deficient, older men receive testosterone $(6,7,8)$. The impact of testosterone replacement on function is less well established.

In 2002, the Institute of Medicine report on testosterone replacement in older men noted few trials and trials of short duration. The committee recommended that future trials focus on health outcomes for which preliminary evidence of efficacy and limited alternative therapies exist, such as frailty (9). Most trials of testosterone replacement have included relatively healthy older men and have not selected men for frailty. We, therefore, undertook this placebo-controlled study in older men with osteoporosis, physical frailty, and low testosterone to determine if testosterone supplementation would affect sex hormone levels, bone, and frailty.

\section{METHODS}

The Institutional Review Board at the University of Connecticut Health Center approved the study, and all men gave written informed consent. Men were recruited using a host of strategies including mailings, talks, and physician referrals. Men were selected for testosterone levels below $350 \mathrm{ng} / \mathrm{dL}$ or bioavailable testosterone levels at least $1.5 \mathrm{SD}$ lower than the young adult mean (95-350 $\mathrm{ng} / \mathrm{dl}$ for men 40-49yrs). Testosterone and bioavailable testosterone were assessed by a single measure at screening, 12 and 24 months. Initially, men over the age of 50 with a nontraumatic hip fracture were included to recruit men with osteoporosis and frailty. To achieve recruitment goals, inclusion criteria were broadened to include men age 60 years or greater who displayed at least one of the five frailty criteria defined by Fried et al. (10) and had a BMD T-score at the hip of -2.0 or less OR had a nontraumatic fracture within the last five years. Exclusion criteria were: 1) Prostate specific antigen level over $6.5 \mathrm{ng} / \mathrm{dl}$ or history of prostate cancer; 2) disease of bone metabolism (i.e., Paget's disease, osteomalacia, hyperparathyroidism);3) history of pituitary disease;4) history of sleep apnea; 5) consumption of more than 3 alcoholic drinks/day; 6) the use of androgen, estrogen or dehydroepiandrosterone in the preceding year; 7) current use of antiresorptive agents such as calcitonin or bisphosphonates; 8) metastatic or advanced cancer; 9) current chemotherapy or radiation treatment; 10 ) advanced liver or renal disease such that the subjects is unlikely to complete the two year intervention; 11) hemoglobin >16.5 g/dl.

Figure 1 outlines the recruitment and retention of study subjects. Included in these numbers, 194 men with a nontraumatic femoral neck fracture were screened, 44 were eligible and entered the study. A total of 131 men were randomly assigned to treatment or placebo. The study was designed as a two-year intervention, but due to delays in recruitment and lack of funds for an extension, limited 24 month follow-up is available. An 'end therapy' time point 
was created for analysis and was defined as men who completed at least 16 months of follow-up (mean $=23$ months, $n=62$ ). Follow-up is available for all men that did not discontinue because of illness or complication $(n=99,75 \%)$ at 12 months.

\section{Treatment}

Men were randomized in a double-masked manner to receive either transdermal testosterone supplementation (5 mg AndroGel ${ }^{\mathrm{TM}} 1 \%$ ) or a matching, indistinguishable placebo gel. The randomization was done using blocked randomization with random block sizes ( 2 or 4 ), stratified by frailty status. Solvay Pharmaceuticals supplied the gel. Gel was labeled and distributed by the research pharmacist who had no direct contact with research participants. Investigators and subjects were unaware of the content of the gel bottles. Compliance assessment included measurement of returned gel bottles and monthly application logs. All men were counseled to maintain calcium intake of $1500 \mathrm{mg} /$ day and received Citrical 315 mg tablets to meet these goals; most men consumed 3-4 tablets per day to supplement their diet. In addition, all men were given 1000 IU cholecalciferol per day.

\section{Evaluations}

Baseline and follow-up evaluations of the following outcomes were performed: sex and calcium regulating hormone levels, bone mineral density (BMD), bone markers, frailty evaluation, strength measures, multiple physical performance measures, body composition, and safety parameters, including prostate examination, hemoglobin levels and cholesterol levels. Calcium and vitamin D intake (including supplements) were estimated by a 3-day food record. Activity was estimated by Physical Activity Scale for the Elderly (PASE) questionnaire (11). The frailty phenotype evaluation was based on Fried et al. (10) (frail =35 characteristics, intermediate frail $=1-2$ characteristics, non-frail $=0$ characteristics). Bone mineral density and body composition (Lunar DPX-L, Madison, WI) of the proximal femur, lumbar spine, distal radius, and total body (total lean body mass [LBM $(\mathrm{kg})]$, total fat mass $(\mathrm{kg})$ and total body bone mineral content $(\mathrm{kg})$ ) were obtained at baseline, 12 months and end therapy. The coefficient of variation of BMD measurement at the proximal femur, spine and total body was $<1 \%, 1.5 \%$ and $2 \%$, respectively. Appendicular skeletal muscle mass (ASM) was determined by combining the lean tissue mass of the regions of the arms and legs, excluding all other regions from analysis (12). We adjusted ASM for height by dividing each by height ${ }^{2}\left(\mathrm{~m}^{2}\right)$. Leg extension strength [1 repetition maximum (13); intra- and intertester variability $<10 \%$ ] was measured on the Keiser Sitting Leg Press. Physical performance was assessed by the Short Physical Performance Battery [ability to rise from a chair, static balance and the 8 foot walk ](14), supine to stand test (15) and Get Up and Go test (16).

Methods for biochemical analysis have been previously described (6) and included markers of bone formation [including bone specific alkaline phosphatase (BAP), N-terminal type I procollagen peptide (PINP) and osteocalcin (OC)]; markers of bone resorption[crosslinked $\mathrm{N}$-telopeptide (NTX) of type I collagenand free deoxypyridinoline crosslinks (DPD)]; sex hormones [total and bioavailable testosterone, SHBG, estradiol, DHEAS]; calcium regulating hormones [25OHD and PTH]; safety measures [cholesterol measurements, hematocrit, and PSA]. Further, prostate evaluation included symptoms of benign prostate hyperplasia assessed using the International Prostate Symptom Score (IPSS) and symptoms of urinary retention were recorded. Sexual function health-related quality of life was recorded using the UCLA Prostate Index questionnaire.

\section{Statistical Analysis}

Baseline and clinical characteristics were reported using means and standard deviations stratified by treatment group. One-way analysis of variance (ANOVA) was used to test the 
difference in baseline characteristics between the treatment groups. Between group changes were detected using one-way analysis of variance. Paired t-tests were used to assess change within each group over time. The intention-to-treat analysis for 12 month data is presented in Table 2. Post hoc analyses were conducted comparing men with $70 \%$ or more compliance for changes in 12 month and end therapy outcomes. Similarly, men with the highest tertile of biotestosterone $(107 \mathrm{ng} / \mathrm{dL})$ in the treatment group were compared with the rest of the group for changes in 12 month and end therapy outcomes. Kaplan-Meier method was used to assess survival time distribution according to testosterone/control groups. Analyses were done using SPSS version 16.0.

\section{RESULTS}

\section{Subject Population and Disposition}

One hundred and thirty-one men, mean age $77.1 \pm 7.6$ years (range $57-95$ years), were randomized into the study; 69 received testosterone gel and 62 received placebo. Thirty-two men (24\%) discontinued at one year and 69 men (53\%) withdrew by end therapy (Figure 1). For the end therapy measure, 62 men were included in the analysis with a mean of 23 months of follow-up (range 16-24 months for these 62 men). Baseline characteristics of the randomized participants are presented in Table 1 . Most men in the study demonstrated some level of physical frailty, $73 \%$ with intermediate frailty, $18 \%$ frail and only $9 \%$ without frailty characteristics; the specific criterion that qualified men as frail are outlined in Table 1. Most men met the criteria for low strength (76\%), followed by low energy output (37\%), with $18-26 \%$ meeting criteria for weight loss, slow walking or sense of exhaustion.

\section{Sex Hormone and Calcium Regulating Hormone Changes}

Baseline and 12-month data for sex hormones and calcium regulating hormones are seen in Table 2 (end therapy data not shown). Testosterone and bioavailable testosterone levels increased in the treatment group at 12-months and end therapy; the group differences trended toward significance for total testosterone at 12 months $(\mathrm{p}=.054)$ and were significant for bioavailable testosterone ( $\mathrm{p}=.001)$. PTH decreased and 25OHD increased in both groups, as expected from calcium/vitamin D supplementation provided to both groups.

\section{Bone Mineral Density and Bone Turnover Markers}

Bone mineral density and bone turnover marker data at baseline and 12 months are shown in Table 2. At 12 months, an increase in L1-L2 BMD of 3.25\% (and of 3.07\% for L1-L4) was seen in the testosterone group. L1-L2 was used to avoid misreading due to structural changes common in the lower lumbar spine due to degenerative joint disease and osteophyte formation. Femoral neck BMD increased in the testosterone group by $1.38 \%$. BMD at other femoral sites and total body did not change. In contrast, mid-radius BMD declined $1.2 \%$ at 12 months in the testosterone treatment group $(\mathrm{p}=.008)$.

Markers of bone turnover, including resorption (6\%) and formation (11\%), decreased from baseline levels in both groups.

\section{Frailty, Body Composition, Muscle Strength and Physical Performance}

The baseline and 12 month data for body composition, upper and lower extremity muscle strength and physical performance are shown in Table 2. The groups were similar at baseline in distribution of frailty status (chi square value $1.831, \mathrm{p}=0.48$ ) and no significant changes in frailty status were detected throughout the study (data not shown). 


\section{Safety Evaluations}

There were 10 (7.6\%) deaths; 3 occurred in the testosterone group and 7 in the placebo group. There were 4 deaths attributed to sudden death, 3 to stroke, 1 to cancer, and 2 of complications following hip fracture or fall. Mortality rates between groups were not statistically different using a chi square test $(\mathrm{p}=.14)$ or Kaplan-Meier survival analysis. The testosterone group had greater mean days survived (645 days vs 436 days), although this did not reach statisitical significance $(\mathrm{p}=0.16)$. After adjusting for age, frailty and BMI, there were no differences in mortality.

The baseline and 12 month values for PSA, IPSS total score, hemoglobin, and cholesterol are presented in Table 2 . Twelve men $(9.2 \%)$ withdrew from treatment for changes in PSA $(\mathrm{n}=8)$, symptoms from prostate $(\mathrm{n}=1)$, difficulty urinating $(\mathrm{n}=2)$ or prostate cancer $(\mathrm{n}=1)$.

Seven individuals withdrew from treatment for signs and symptoms consistent with cardiac disease $(5.3 \%)$ including myocardial infarction $(n=2)$, congestive heart failure $(n=3)$, and significant lower extremity edema $(n=2)$. No significant changes in hemoglobin or hematocrit were seen between groups although one individual discontinued treatment due to rise in hemoglobin from $47.6 \%$ to $52.5 \%$.

\section{Treatment Compliance}

Overall compliance with study medication was $54 \%$ of prescribed gel at 12 month and $56 \%$ at end therapy. Twenty-three (40\%) of placebo users and 26 (38.8\%) testosterone users had $70 \%$ or greater compliance at 12 months (chi square $=0.031 ; \mathrm{p}=0.861)$; similar compliance was reported at end therapy (40\% placebo and $49 \%$ testosterone) (chi square 1.057; $\mathrm{p}=0.304)$. Re-analyses of outcome data was not different when using only those with $70 \%$ compliance. In the sample of 25 men with compliance of $80 \%$ or greater, outcomes remained similar to the intention-to-treat analysis, although statistical significance was detected in the loss of fat mass and gain in lean mass and changes in hand-grip strength including a gain of $14 \%$ in the testosterone group and a loss of $7.5 \%$ in the placebo group. Post-hoc analysis was performed using the highest tertile of bioavailable testosterone levels (bioavailable testosterone of $107 \mathrm{ng} / \mathrm{dl}$ or greater) without differences from the intention-totreat analysis. Data for the post-hoc analysis of $70 \%$ compliance, $80 \%$ compliance and highest/lowest tertile is not shown. Finally, drop-out rates among the frailty categories were $42 \%$ in non-frail, $55 \%$ in intermediate frail and 58\% in frail individuals (chi-square .936; $\mathrm{p}=0.626$ ).

\section{DISCUSSION}

This study of predominantly frail, older men with low bone mass, treated with transdermal testosterone gel demonstrated increased testosterone levels, positive changes in axial bone mineral density and no changes in muscle strength or physical performance, although compliance with study medication (testosterone or placebo) was only modest. Body composition changes, including a decline in fat mass and an increase in lean mass, were favorable. Overall, there were no differences in side effects between the testosterone and placebo groups in the 12 to 24 month intervention.

\section{Bone}

There was a small effect of transdermal testosterone therapy on spine BMD in older, frail men selected for low bone mineral density or fracture, but no appreciable effect at the hip and a decrease in BMD at the wrist. While the increase in spinal BMD is promising, the reasons for the overall lack of effect of testosterone on bone may be numerous. The dose may have not been sufficient to cause an effect, as the study with the largest change in bone 
had the highest serum testosterone levels (8). Further, the testosterone insufficiency in our study may not have been great enough to demonstrate an effect. Snyder et al. (7) only found an effect of testosterone replacement on bone in men with a total testosterone below $200 \mathrm{ng} /$ dl. Another study found an effect in men with a testosterone level 3 SD below the young adult mean (3), although others have found change in BMD in men with less severe deficiency $(6,8)$. The mode of testosterone replacement may also be important, but too few studies using various testosterone preparations have been done to address this question (9). Finally, testosterone therapy may not be a robust therapy for improving bone mineral density in frail, older men. Information on fracture prevention is not available from this or other studies, but in this study that targeted men with low bone mass/osteoporosis and frailty did not result in large changes in outcomes intermediate to fracture.

\section{Muscle and body composition changes}

We found a decrease in fat mass and an increase in lean and skeletal muscle mass. Results similar to these were found in other studies reviewed in two recent meta-analyses $(17,18)$. The effects of testosterone replacement on muscle strength and function have not been as consistent, although the meta-analyses report increases in hand-grip strength $(17,18)$ and dominant leg extension strength (17). Some have postulated that the lack of consistent effect is due to use of testosterone in healthy men; we found no advantage to testosterone supplementation in men selected for frailty. We may have missed a favorable effect due to inadequate increases in testosterone levels, since a dose-response of muscle to testosterone has been demonstrated (19). In the few trials of older men treated with testosterone, only two have demonstrated an increase in hand muscle strength $(2,30)$ and none has demonstrated improvement over placebo in lower extremity strength $(6,21,22)$. Beneficial effects of testosterone on protein uptake and satellite cell production are seen in ex-vivo studies $(23,24)$, but these benefits have not resulted in clinically meaningful improvements in the muscle of older men.

Further, we did not find improvement in the physical function. The men had impaired baseline physical performance compared to other studies of men treated with testosterone. A prospective 4 year study demonstrated that those with baseline SPPB score of 8 had subsequent decline in function (14). The men in our study had baseline SPPB scores of 8. The mean Get Up and Go Test score of $12.7 \mathrm{sec}$ is slower than $8 \mathrm{sec}$ in the normal elderly population (16) and is at a level $(13 \mathrm{sec})$ that predicts those at high risk of falls (25). Most other studies have not shown benefit in physical performance from testosterone therapy in older men $(2,21,26)$. In contrast, Page et al. (20) found an increase in a composite physical performance score following 3 years of intramuscular testosterone treatment in healthy older men (with baseline Get Up and Go test score of $4 \mathrm{sec}$ ). Future studies will need to address whether older frail men improve physical performance with higher doses of testosterone, as demonstrated by Page et al. in healthy, older men (20).

\section{Hypogonadism}

The prevalence of hypogonadism is not known with certainty, but estimates range from $6 \%$ to $43.7 \%(27,28)$. In our population of frail men, selected for osteoporosis, all but one man met the cut off for low testosterone (defined as total or bioavailable testosterone 1.5 SD lower than mean of young adult men). Using the Institute of Medicine definition of hypogonadism [low testosterone in combination with symptoms (eg., frailty or osteoporosis)], nearly all men we evaluated met the definition. Although the efficacy and safety of testosterone remains to be determined in older frail men, the association between osteoporosis, frailty and low testosterone levels is clearly present. 


\section{Dose}

The increases in testosterone levels achieved in this study were modest. The mean total and bioavailable testosterone levels achieved were $583 \mathrm{ng} / \mathrm{dL}$ and $157 \mathrm{ng} / \mathrm{dL}$, respectively. The Endocrine Society Clinical Task Force recommends achieving testosterone levels in midnormal range and adjusting the dose if levels below $350 \mathrm{ng} / \mathrm{dl}$ are found (29). We did not adjust dosage for testosterone levels. Twenty percent of men in the testosterone group had testosterone levels less than $350 \mathrm{ng} / \mathrm{dL}$ at 12 months. The largest changes in bone mineral density, body composition and physical performance in older men were achieved in a study in which testosterone levels were $734 \mathrm{ng} / \mathrm{dl}$ and $942 \mathrm{ng} / \mathrm{dL}$ (8). Another study that found gains in BMD only in men with baseline testosterone levels below $200 \mathrm{ng} / \mathrm{dl}$ achieved serum levels of $625 \mathrm{ng} / \mathrm{dl}$ using a transdermal patch (7). Further study is warranted to understand whether the mode of delivery or a dose threshold must be met to improve bone and muscle function in frail older men with low testosterone levels.

\section{Safety}

Several men discontinued participation because of prostate signs and symptoms, but this occurred in both groups. The Institute of Medicine concluded the influence of testosterone on prostate outcomes are poorly defined but influence the decision to supplement individuals (9). A meta-analysis by Calof et al. (30) found an increased risk of prostate events (pooled OR 1.78; CI 1.07-2.95) in approximately 1000 men over age 45 years receiving testosterone or placebo, but no individual differences in prostate biopsies, prostate cancer, PSA increases $>4 \mu \mathrm{g} / \mathrm{ml}$, changes in IPSS score or urinary retention. The authors caution that more biopsies may have unmasked subclinical prostate cancer.

We found no differences in cholesterol levels or cardiovascular events between the testosterone and placebo groups. Deaths from sudden death or stroke were predominant but not different between groups, consistent with findings from other studies performed in healthy men (30). Finally, we found no increase in hematocrit, a change shown to be dose dependent (19), suggesting that we did not alter testosterone levels to a sufficient extent to cause adverse events.

Compliance-The compliance with gel was similar in both groups, resulting in modest changes in testosterone levels. While testosterone levels increased into the young adult normal range in most the men, more robust outcomes might have been observed if higher serum levels had been achieved. While most men completed 12 months, the drop out rate for the 24 month end point was large. The rate was similar in both groups and men discontinued early in their participation, suggesting baseline frailty of the men may have been a contributing factor. Over $7 \%$ of the men died and multiple serious medical problems occurred in this population. Only $8(6 \%)$ men dropped from the study for lost of interest. Historically, many chronically ill or frail adults were excluded from clinical trials (29). Our goal was to follow recommendations of the Interventions on Frailty Working Group, convened by the National Institute on Aging, that suggest multiple step screening to select individuals not too ill (or too well) to participate (31). The majority of individuals selected displayed intermediate frailty. This population may have been too impaired to successfully participate in a two year clinical trial and to benefit from the intervention. Further research is required to understand the best approach to intervention trials in frail adults, although the men that dropped out were not only frail but distributed throughout the study population. Much of the low compliance (both in use of gel and in drop-out rates) was due to intervening medical conditions. 


\section{Limitations and Strengths}

This study has several limitations. The men selected for the study may not have had hypogonadism to a degree that would benefit from testosterone treatment. The dose of testosterone delivered may not have been adequate to provide improvement in bone, muscle, or physical performance. The mode of delivery may have delivered testosterone in a way that was not beneficial or did not result in peak levels that may be required to see changes in bone and physical performance. Further, the mode of delivery may have limited compliance with the treatment. The number of men that left the study, due to non-contributory illnesses or other non-treatment related issues, was large, limiting the ability to obtain meaningful results. The strengths of the study are also present. The men were selected predominantly for fracture or low bone mass and evidence of frailty, a population for which the benefits of testosterone have been postulated for years. Information on clinical trials in this population was obtained including the high drop out rate due to medical co-morbidities. The study was a lesson in the practical challenges that will likely be encountered in clinical practice if a provider and patient decide to undertake testosterone supplementation. This information will aid in future trials addressing frail, older men. To minimize bias, we powered the study with the expectation for a 50\% drop-out rate and selected intention-to-treat analysis.

\section{Conclusion}

Older, frail men, a group with potential to benefit from testosterone supplementation, had favorable changes in body composition and axial bone mineral density, but no substantial changes in femur bone density, muscle strength or physical performance. These effects may be explained by modest compliance and testosterone levels in the low to midrange of young adults. Further study of testosterone therapy in older, frail men will be required to more completely understand the risk and benefits of testosterone in this population.

\section{Acknowledgments}

In addition, we wish to thank Lawrence G. Raisz, M.D., for careful reading of the manuscript and a lifetime of mentoring; the physicians of Orthopedic Associates for assistance in recruitment of men with hip fractures; Pamela Fall and Christine Abreu for assistance in running the biochemical assays; Brad Biskup, Valerie Smith, Glenn Marcella and Nancy Dean for tireless work in the completion of the study; the Data and Safety Monitoring Board for careful attention to study mechanics; and finally the men who participated in the study for their altruism and participation.

This work has been supported by the NIH R01 AG1, General Clinical Research Center (MO1-RR06192) and the Claude Pepper OAIC (5P60-AG13631). Testosterone and placebo gel was provided by Solvay Pharmaceuticals at no charge to the study.

Sponsor's role: We certify that all affiliations with or financial involvement with any organization with a financial interest are disclosed.

\section{References}

1. Ferrini RL, Barrett-Connor E. Sex hormones and age: a cross-sectional study of testosterone and estradiol and their bioavailable fractions in community-dwelling men. Am J Epidemiol. 1998; 147:750-754. [PubMed: 9554416]

2. Gray A, Berlin JA, McKinlay JB, Longcope C. An examination of research design effects on the association of testosterone and aging: results of a meta-analysis. J Clin Epidemiol. 1991; 44:671684. [PubMed: 1829756]

3. Morley JE, Perry HM 3d, Kaiser FE, et al. Effects of testosterone replacement therapy in old hypogonadal males: A preliminary study. J Am Geriatr Soc. 1993; 41:149-152. [PubMed: 8426037]

4. Tenover JS. Effects of testosterone supplementation in the aging male. J Clin Endocrinol Metab. 1992; 75:1092-1098. [PubMed: 1400877] 
5. Mohr BA, Bhasin S, Kupelian V, et al. Testosterone, sex hormone-binding globulin, and frailty in older men. J Am Geriatr Soc. 2007; 55:548-555. [PubMed: 17397433]

6. Kenny AM, Prestwood KM, Gruman CA, et al. Effects of transdermal testosterone on bone and muscle in older men with low bioavailable testosterone levels. J Gerontol. 2001; 56A:M266-M272.

7. Snyder PJ, Peachey H, Hannoush P, et al. Effect of testosterone treatment on bone mineral density in men over 65 years of age. J Clin Med Endocrinol. 1999; 84:1966-1972.

8. Amory JK, Watts NB, Easley KA, et al. Exogenous testosterone or testosterone with finasteride increases bone mineral density in older men with low serum testosterone. J Clin Endocrinol Metab. 2004; 89:503-510. [PubMed: 14764753]

9. Institute of Medicine. Testosterone and Aging: Clinical Research Directions. Committee on Assessing the Need for Clinical Trials of Testosterone Replacement Therapy. Washington, DC: National Academies Press; 2003.

10. Fried LP, Tangen CM, Walston J, et al. Frailty in older adults: evidence for a phenotype. J Gerontol A Biol Sci Med Sci. 2001; 56A:M146-156. [PubMed: 11253156]

11. Washburn RA, Smith KW, Jette AM, et al. The physical activity scale for the elderly (PASE): Development and evaluation. J Clin Epidemiol. 1993; 46:153-162. [PubMed: 8437031]

12. Wang ZM, Visser M, Ma R, et al. Skeletal muscle mass: Evaluation of neutron activation and dualenergy X-ray absorptiometry methods. J Appl Physiol. 1996; 80:824-831. [PubMed: 8964743]

13. Judge JO, Schechtman K, Cress E. the FICSIT Group. The relationship between physical performance measures and independence in Instrumental Activities of Daily Living. J Am Geriatr Soc. 1996; 44:1332-1341. [PubMed: 8909349]

14. Guralnik JM, Branch LG, Cummings SR, et al. Physical performance measures in aging research. J Gerontol. 1989; 44:M141-M146. [PubMed: 2768767]

15. Alexander NB, Ulbrich J, Raheja A, et al. Rising from the floor in older adults. J Am Geriatr Soc. 1997; 45:564-569. [PubMed: 9158576]

16. Podsiadlo D, Richardson S. The timed "Up \& Go": A test of basic functional mobility for frail elderly persons. J Am Geriatr Soc. 1991; 39:142-148. [PubMed: 1991946]

17. Isidori AM, Giannetta E, Greco EA, et al. Effects of testosterone on body composition, bone metabolism and serum lipid profile in middle-aged men: A meta-analysis. Clin Endocrinol. 2005; 63:280-293.

18. Bhasin S, Calof OM, Storer TW, et al. Drug insight: Testosterone and selective androgen receptor modulators as anabolic therapies for chronic illness and aging. Nat Clin Pract Endocrinol Metab. 2006; 2:146-159. [PubMed: 16932274]

19. Bhasin S, Woodhouse L, Casaburi R, et al. Older men are as responsive as young men to the anabolic effects of graded doses of testosterone on the skeletal muscle. J Clin Endocrinol Metab. 2005; 90:678-688. [PubMed: 15562020]

20. Page ST, Amory JK, Bowman FD, et al. Exogenous testosterone (T) alone or with finasteride increases physical performance, grip strength, and lean body mass in older men with low serum $\mathrm{T}$. J Clin Endocrinol Metab. 2005 Mar.90:1502-1510. [PubMed: 15572415]

21. Snyder PJ, Peachey H, Hannoush P, et al. Effect of testosterone treatment on body composition and muscle strength in men over 65 years of age. J Clin Endocrinol Metab. 1999; 84:2647-2653. [PubMed: 10443654]

22. Blackman MR, Sorkin JD, Münzer T, et al. Growth hormone and sex steroid administration in healthy aged women and men: A randomized controlled trial. JAMA. 2002; 288:2282-2292. [PubMed: 12425705]

23. Sinha-Hikim I, Roth SM, Lee MI, et al. Testosterone-induced muscle hypertrophy is associated with an increase in satellite cell number in healthy, young men. Am J Physiol Endocrinol Metab. 2003; 285:E197-205. [PubMed: 12670837]

24. Urban RJ, Bodenburg YH, Gilkison C, et al. Testosterone administration to elderly men increases skeletal muscle strength and protein synthesis. Am J Physiol. 1995; 269:E820-E826. [PubMed: 7491931]

25. Shumway-Cook A, Brauer S, Woollacott M. Predicting the probability for falls in communitydwelling older adults using the Timed Up \& Go test. Physical Ther. 2000; 80:896-903. 
26. Emmelot-Vonk MH, Verhaar HJ, Nakhai Pour HR. Effect of testosterone supplementation on functional mobility, cognition, and other parameters in older men: A randomized controlled trial. JAMA. 2008 Jan 2.299:39-52. [PubMed: 18167405]

27. Araujo AB, O'Donnnell AB, Brambilla DJ, et al. Prevalence and incidence of androgen deficiency in middle-aged and older men: Estimates from the Massacheuetts Male Study. J Clin Endocrinol Metab. 2004; 89:5920-5926. [PubMed: 15579737]

28. Dhindsa S, Prabhakar S, Sethi M, et al. Frequent occurrence of hypogonadotropic hypogonadism in type 2 diabetes. J Clin Endocrinol Metab. 2004; 89:5462-5468. [PubMed: 15531498]

29. Bhasin S, Cunningham GR, Hayes FJ, et al. Testosterone therapy in adult men with androgen deficiency syndromes: An Endocrine Society Clinical Practice Guideline. J Clin Endocrin Metab. 2006; 91:1995-2010.

30. Calof OM, Singh AB, Lee ML, et al. Adverse events associated with testosterone replacement in middle-aged and older men: A systematic review of randomized, placebo-controlled trials. J Gerontol A Biol Sci Med Sci. 2005; 60:1451-1457. [PubMed: 16339333]

31. Ferrucci L, Guralnik JM, Studenski S, et al. Interventions on Frailty Working Group. Designing randomized, controlled trials aimed at preventing or delaying functional decline and disability in frail, older persons: A consensus report. J Am Geriatr Soc. 2004; 52:625-634. [PubMed: 15066083] 


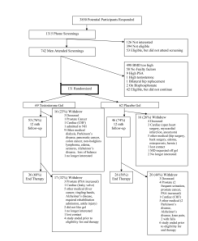

Figure 1.

Schematic of enrollment and retention patterns of research volunteers who participated in the study. 
Table 1

Characteristics of Study Subjects

\begin{tabular}{|c|c|c|c|c|}
\hline & Testosterone (69) & Control (62) & Total (131) & $P$ value \\
\hline Basic Demographics & Mean \pm SD & Mean \pm SD & Mean \pm SD & \\
\hline Age (years) & $77.9 \pm 7.3$ & $76.3 \pm 8.0$ & $77.1 \pm 7.6$ & 0.26 \\
\hline BMI $\left(\mathrm{kg} / \mathrm{m}^{2}\right)$ & $27.2 \pm 4.3$ & $26.6 \pm 4.2$ & $26.9 \pm 4.3$ & 0.44 \\
\hline Calcium intake (mg/d) & $1311 \pm 877$ & $1331 \pm 774$ & $1320 \pm 826$ & 0.90 \\
\hline Vitamin D intake (mg/d) & $711 \pm 517$ & $651 \pm 499$ & $682 \pm 507$ & 0.51 \\
\hline Frailty Categorization & $\%(\mathrm{~N})$ & $\%(\mathbf{N})$ & $\%(\mathbf{N})$ & 0.48 \\
\hline None ( 0 characteristics) & $10(7)$ & $8(5)$ & $9(12)$ & \\
\hline Intermediate ( $1-2$ char) & $68(47)$ & $77(48)$ & $73(95)$ & \\
\hline Frail ( $3-5$ char) & $22(15)$ & $14(9)$ & $18(24)$ & \\
\hline Frailty Characteristics & $\%(\mathrm{~N})$ & $\%(\mathrm{~N})$ & $\%(\mathrm{~N})$ & \\
\hline Hand-grip strength & $81(56)$ & $71(44)$ & $76(100)$ & .17 \\
\hline Weight loss & $12(8)$ & $16(10)$ & $14(18)$ & .49 \\
\hline Walk speed & $22(15)$ & $18(11)$ & $20(26)$ & .51 \\
\hline Activity level & $30(21)$ & $27(16)$ & $29(37)$ & .64 \\
\hline Sense of Exhaustion & $15(10)$ & $19(12)$ & $17(22)$ & .48 \\
\hline Medical Conditions & $\%(\mathrm{~N})$ & $\%(\mathbf{N})$ & $\%(\mathbf{N})$ & \\
\hline Hypertension & $22(15)$ & $24(15)$ & $23(30)$ & 0.81 \\
\hline Coronary artery disease & $24(16)$ & $36(22)$ & $30(38)$ & 0.15 \\
\hline Diabetes mellitus & $12(8)$ & $10(6)$ & $11(14)$ & 0.68 \\
\hline Allergies & $16(11)$ & $21(13)$ & $19(24)$ & 0.51 \\
\hline Cancer & $15(10)$ & $5(3)$ & $10(13)$ & 0.06 \\
\hline Depression & $15(10)$ & $11(7)$ & $13(17)$ & 0.54 \\
\hline Muscle Aches & $21(14)$ & $26(16)$ & $23(30)$ & 0.51 \\
\hline Hearing Problems & $36(24)$ & $21(13)$ & $29(37)$ & 0.06 \\
\hline Osteoarthritis & $19(13)$ & $21(13)$ & $20(26)$ & 0.83 \\
\hline Joint Pain & $33(22)$ & $29(18)$ & $31(40)$ & 0.64 \\
\hline History of Fracture & $\%(\mathrm{~N})$ & $\%(\mathbf{N})$ & $\%(\mathbf{N})$ & \\
\hline Hip (or Pelvis) & $37(25)$ & $31(19)$ & $34(44)$ & 0.43 \\
\hline Wrist & $8(5)$ & $10(6)$ & $9(11)$ & 0.67 \\
\hline Spine & $2(1)$ & $2(1)$ & $2(2)$ & 0.96 \\
\hline Hormones & Mean \pm SD & Mean \pm SD & Mean \pm SD & \\
\hline Total Testosterone $\mathrm{ng} / \mathrm{dL}$ & $380.4 \pm 179.5$ & $417.8 \pm 192.5$ & $398.0 \pm 185.9$ & 0.25 \\
\hline Biotestosterone $\mathrm{ng} / \mathrm{dL}$ & $58.9 \pm 28.1$ & $65.5 \pm 31.0$ & $62.1 \pm 29.6$ & 0.21 \\
\hline Estradiol pg/mL & $35.4 \pm 11.2$ & $32.8 \pm 8.5$ & $34.2 \pm 10.0$ & 0.14 \\
\hline SHBG ug/dL & $1.5 \pm 0.6$ & $1.5 \pm 0.7$ & $1.5 \pm 0.6$ & 0.76 \\
\hline DHEA ug/dL & $62.2 \pm 46.8$ & $47.1 \pm 41.6$ & $55.0 \pm 44.9$ & 0.055 \\
\hline 25 Hydroxyvitamin D nmol/L & $88.3 \pm 36.6$ & $83.8 \pm 36.2$ & $86.2 \pm 36.3$ & 0.48 \\
\hline
\end{tabular}




\begin{tabular}{|c|c|c|c|c|}
\hline & Testosterone (69) & Control (62) & Total (131) & $P$ value \\
\hline iPTH pg/mL & $70.4 \pm 55.4$ & $68.8 \pm 37.4$ & $69.7 \pm 47.7$ & 0.85 \\
\hline Bone mineral density (g/cm2) & Mean \pm SD & Mean \pm SD & Mean \pm SD & \\
\hline Femoral Total BMD & $0.890 \pm 0.108$ & $0.881 \pm 0.119$ & $0.886 \pm 0.113$ & 0.61 \\
\hline Femoral Neck BMD & $0.794 \pm 0.097$ & $0.795 \pm 0.100$ & $0.794 \pm 0.098$ & 0.93 \\
\hline Trochanter BMD & $0.802 \pm 0.118$ & $0.783 \pm 0.123$ & $0.793 \pm 0.120$ & 0.37 \\
\hline Spine L1-L2 BMD & $1.146 \pm 0.206$ & $1.111 \pm 0.170$ & $1.129 \pm 0.190$ & 0.30 \\
\hline Spine L2-L4 BMD & $1.248 \pm 0.233$ & $1.221 \pm 0.210$ & $1.235 \pm 0.222$ & 0.50 \\
\hline Forearm Mid Radius BMD & $0.727 \pm 0.085$ & $0.721 \pm 0.093$ & $0.724 \pm 0.089$ & 0.70 \\
\hline Whole Body BMD & $1.157 \pm 0.094$ & $1.162 \pm 0.094$ & $1.159 \pm 0.0937$ & 0.75 \\
\hline Bone Turnover Markers & Mean \pm SD & Mean \pm SD & Mean \pm SD & \\
\hline $\mathrm{NTX} / \mathrm{CR} \mathrm{nmol} / \mathrm{mmol}$ & $45.1 \pm 52.2$ & $41.0 \pm 26.9$ & $43.2 \pm 41.8$ & 0.58 \\
\hline $\mathrm{DPD} / \mathrm{CR} \mathrm{ng} / \mathrm{mL}$ & $5.6 \pm 2.1$ & $5.4 \pm 2.4$ & $5.5 \pm 2.3$ & 0.67 \\
\hline BAP U/L & $27.3 \pm 19.8$ & $24.6 \pm 9.8$ & $26.0 \pm 15.9$ & 0.35 \\
\hline Osteocalcin $\mathrm{ng} / \mathrm{mL}$ & $10.8 \pm 7.4$ & $10.8 \pm 6.4$ & $10.8 \pm 6.9$ & 0.98 \\
\hline P1NP ug/L & $51.9 \pm 49.9$ & $45.8 \pm 23.9$ & $49.0 \pm 39.8$ & 0.38 \\
\hline Body Composition & Mean \pm SD & Mean \pm SD & Mean \pm SD & \\
\hline Whole Body Fat (\%) & $28.4 \pm 7.7$ & $28.4 \pm 7.4$ & $28.4 \pm 7.5$ & 0.97 \\
\hline Whole Body Lean (Kg) & $53.4 \pm 6.2$ & $52.7 \pm 7.5$ & $53.1 \pm 6.8$ & 0.58 \\
\hline Appendicular Skeletal Mass (Kg) & $22.7 \pm 3.2$ & $22.3 \pm 3.8$ & $22.5 \pm 3.5$ & 0.61 \\
\hline Strength & Mean \pm SD & Mean \pm SD & Mean \pm SD & \\
\hline Hand Grip Strength $(\mathrm{Kg})$ & $25.1 \pm 7.9$ & $25.6 \pm 8.5$ & $25.3 \pm 8.2$ & 0.72 \\
\hline Leg Strength (Newtons) & $710 \pm 205$ & $665 \pm 225$ & $689 \pm 215$ & 0.25 \\
\hline Leg Power (Watts) & $266 \pm 136$ & $264 \pm 142$ & $265 \pm 138$ & 0.94 \\
\hline Physical Performance & Mean \pm SD & Mean \pm SD & Mean \pm SD & \\
\hline Physical Activity Score & $189.7 \pm 126.3$ & $187.6 \pm 142.7$ & $188.7 \pm 133.6$ & 0.93 \\
\hline Kilocalories & $904 \pm 758$ & $781 \pm 605$ & $846 \pm 691$ & 0.33 \\
\hline SPPB score & $9.0 \pm 2.8$ & $9.2 \pm 2.3$ & $9.1 \pm 2.6$ & 0.69 \\
\hline Walk Speed in $8 \mathrm{ft}(\mathrm{m} / \mathrm{sec})$ & $0.85 \pm 0.24$ & $0.94 \pm 0.22$ & $0.89 \pm 0.23$ & 0.035 \\
\hline Chair rise time (sec) & $15.9 \pm 7.4$ & $14.8 \pm 5.0$ & $15.4 \pm 6.4$ & 0.33 \\
\hline Single leg stance (sec) & $8.8 \pm 9.1$ & $10.2 \pm 9.6$ & $9.5 \pm 9.3$ & 0.41 \\
\hline Supine to Stand (sec) & $7.7 \pm 6.8$ & $8.0 \pm 7.5$ & $7.8 \pm 7.1$ & 0.82 \\
\hline Get up and go test (sec) & $14.3 \pm 10.1$ & $10.8 \pm 4.0$ & $12.7 \pm 8.0$ & 0.015 \\
\hline Lipids & Mean \pm SD & Mean \pm SD & Mean \pm SD & \\
\hline Total Cholesterol mg/dL & $184 \pm 39$ & $192 \pm 37$ & $188 \pm 38$ & 0.25 \\
\hline $\mathrm{HDL} \mathrm{mg} / \mathrm{dL}$ & $45.1 \pm 11.7$ & $45.7 \pm 13.4$ & $45.4 \pm 12.5$ & 0.78 \\
\hline $\mathrm{LDL} \mathrm{mg} / \mathrm{dL}$ & $117.1 \pm 34.2$ & $121.0 \pm 32.6$ & $119.0 \pm 33.4$ & 0.52 \\
\hline Triglycerides mg/dL & $118 \pm 85$ & $119 \pm 62$ & $119 \pm 75$ & 0.90 \\
\hline Prostate, Safety and Quality of Life & Mean \pm SD & Mean \pm SD & Mean \pm SD & \\
\hline Depression CESD score & $7.1 \pm 7.3$ & $7.7 \pm 6.4$ & $7.4 \pm 6.8$ & 0.58 \\
\hline
\end{tabular}




\begin{tabular}{|l|c|c|c|c|}
\hline & Testosterone (69) & Control (62) & Total (131) & P value \\
\hline IPSS prostate symptom score & $8.1 \pm 6.1$ & $8.5 \pm 6.0$ & $8.3 \pm 6.0$ & 0.69 \\
\hline IPSS quality of life & $2.96 \pm 1.33$ & $3.05 \pm 1.34$ & $3.00 \pm 1.33$ & 0.70 \\
\hline UCLA Prostate Index & $20.0 \pm 7.6$ & $19.8 \pm 7.2$ & $19.93 \pm 7.34$ & 0.89 \\
\hline PSA (ug/L) & $2.15 \pm 1.52$ & $2.01 \pm 1.31$ & $2.08 \pm 1.42$ & 0.58 \\
\hline Hematocrit \% & $41.6 \pm 4.2$ & $41.7 \pm 4.5$ & $41.6 \pm 4.3$ & 0.84 \\
\hline
\end{tabular}

BMI -body mass index; SHBG -sex hormone binding globulin; DHEA -dehydroepiandrosterone; iPTH -intact parathyroid hormone; BMD- bone mineral density; NTX/CR -n-telopeptide/creatinine; DPD/CR -deoxypyridinoline/creatinine; BAP-bone specific alkaline phosphatase; P1NP procollagen peptide of type I collagen; SPPB -short physical performance battery; HDL -high density lipoprotein; LDL -low density lipoprotein; CESD- Center for Epidemiologic Studies -Depression; IPSS -International Prostate Symptom Score; UCLA -University of California, Los Angeles; PSA -prostate specific antigen; 


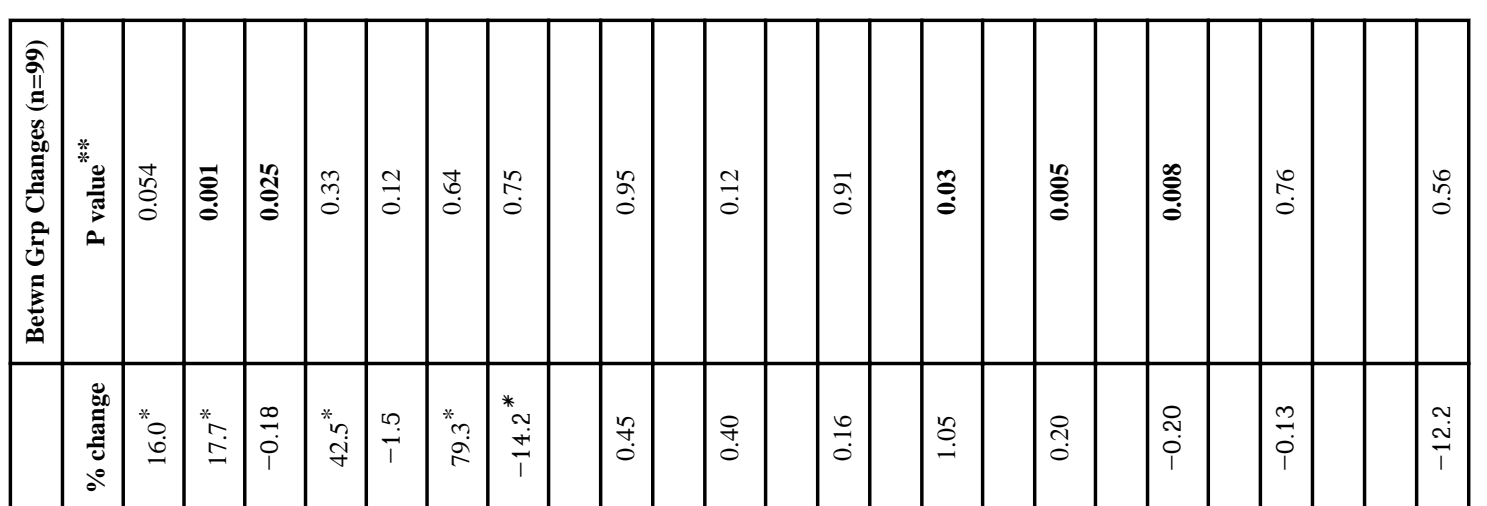

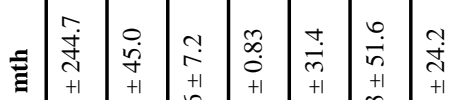

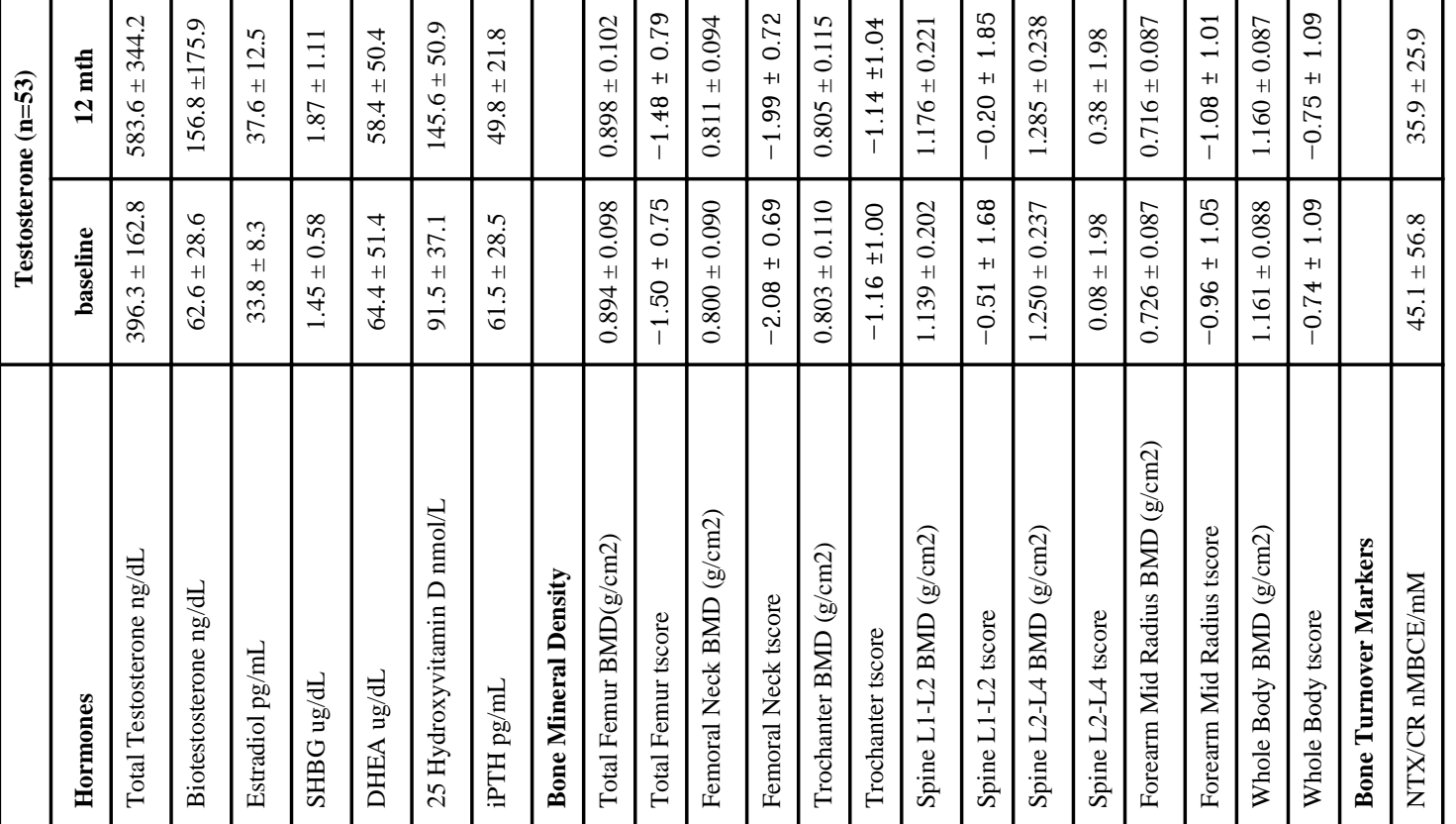



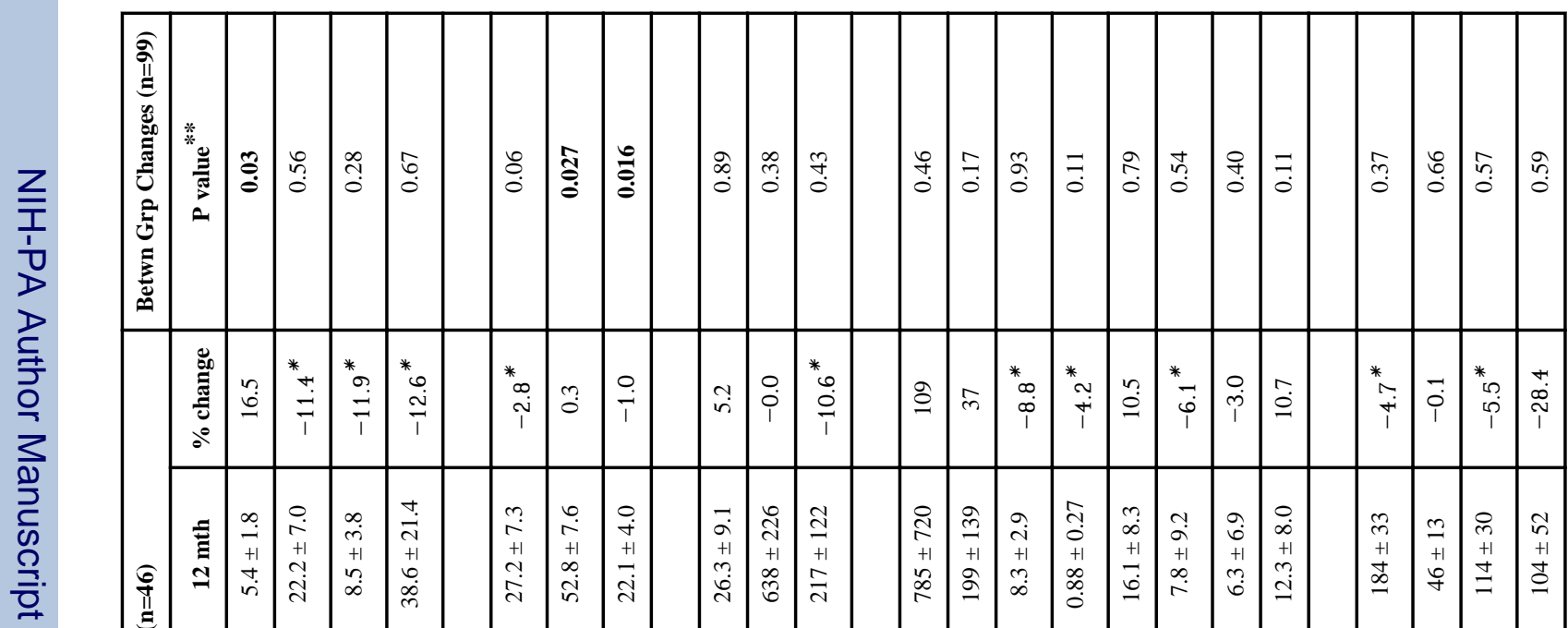

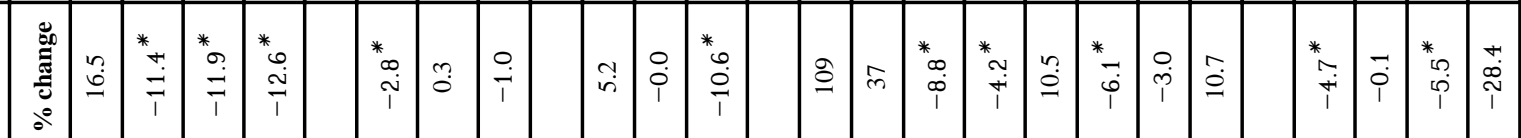

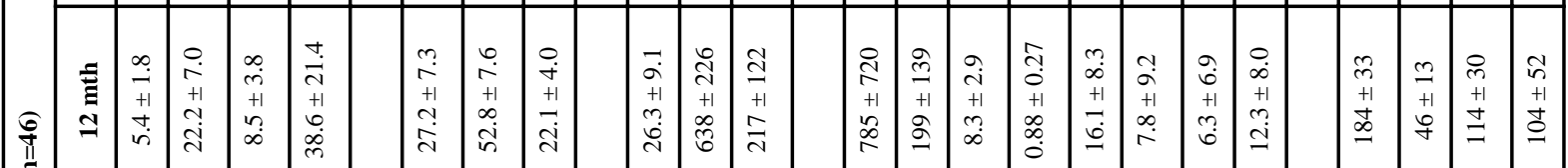

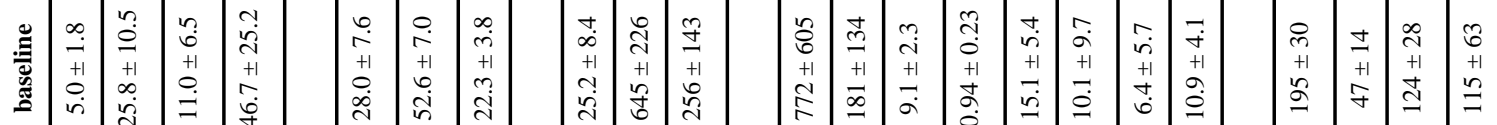

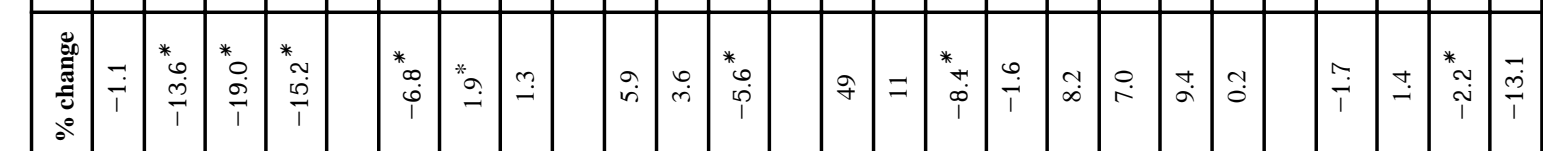

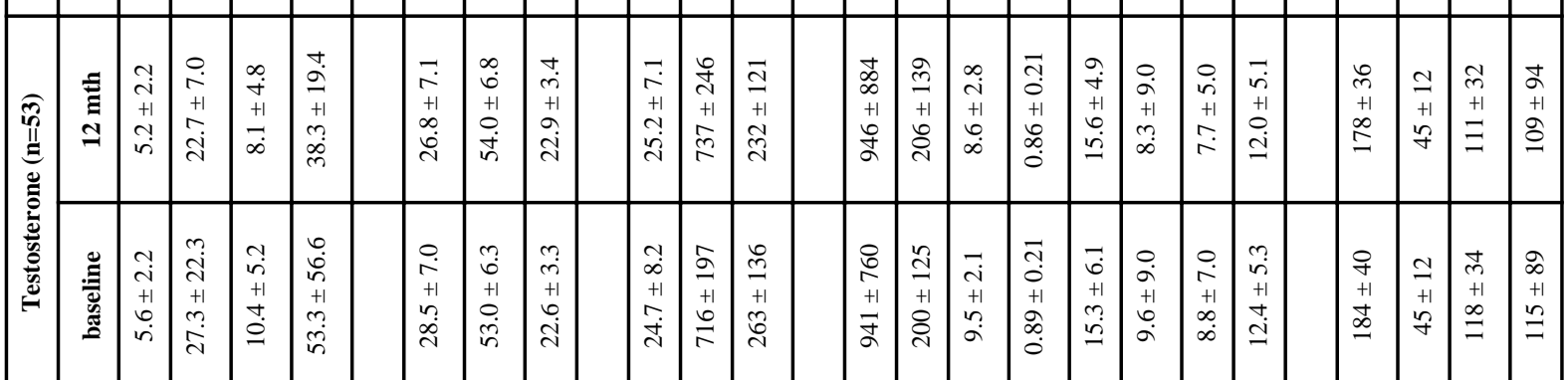




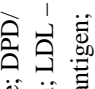

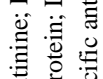

递

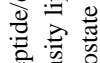

응

施范

苍富

z

窟号

记

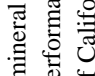

ह

可

定

m.

政

อ 产

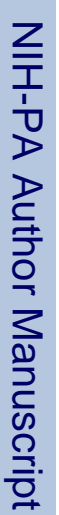

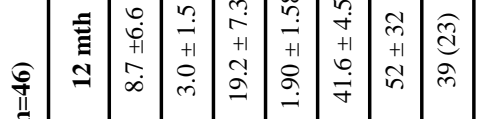

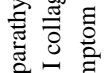

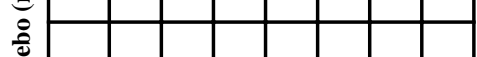

要

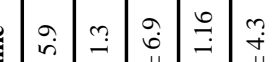

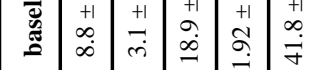

\begin{tabular}{|c|c|c|c|c|c|c|}
\hline 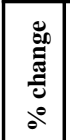 & $\begin{array}{l}0 \\
\dot{i} \\
\end{array}$ & $\stackrel{\circ}{i}$ & $\stackrel{\circ}{\circ}$ & $\stackrel{\infty}{\stackrel{\infty}{a}}$ & $\stackrel{+}{-}$ & \\
\hline$\underline{\Xi}$ & $\begin{array}{l}0 \\
\text { in } \\
+1 \\
0\end{array}$ & $\frac{m}{+1}$ & $\mid \begin{array}{c}\hat{q} \\
+1 \\
n\end{array}$ & +1 & $\mid \begin{array}{l}a \\
\dot{j} \\
+1\end{array}$ & $\begin{array}{l}2 \\
+1 \\
+1\end{array}$ \\
\hline
\end{tabular}

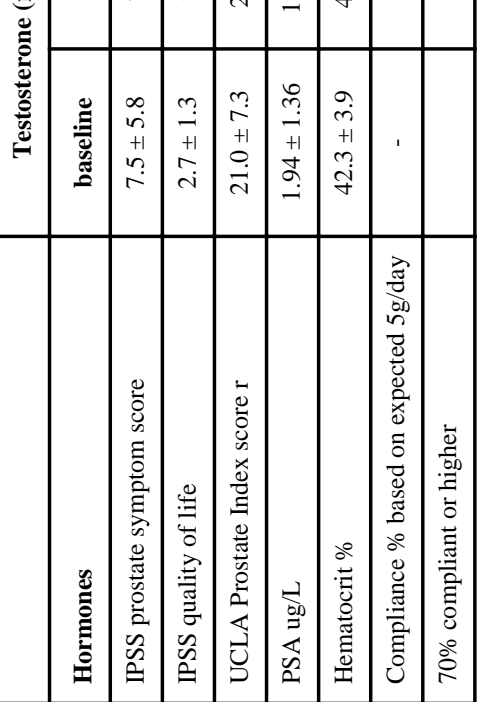

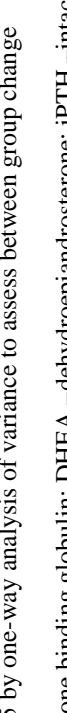

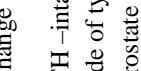

늘

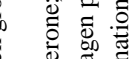

toํ을

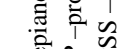

要

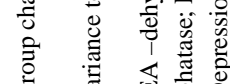

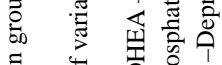

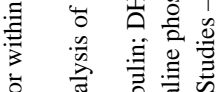

范

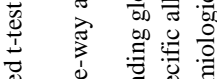

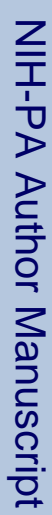

范

b)

它

范

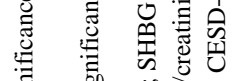

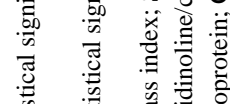

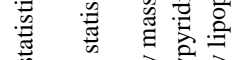

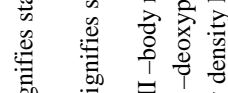

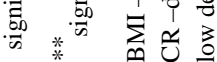

